\title{
Reference Group
}

National Cancer Institute

\section{Source}

National Cancer Institute. Reference Group. NCI Thesaurus. Code C161321.

The study population that is defined for the purpose of comparison to the population under investigation. 